\title{
Effects of Germination and Fermentation on the Functionality of Whole Soy Flour
}

\author{
Livia PATRASCU ${ }^{1}$, Iuliana BANU ${ }^{1}$, Ina VASILEAN ${ }^{1}$ and Iuliana APRODU ${ }^{1 *}$ \\ ${ }^{1}$ Faculty of Food Science and Engineering, Dunarea de Jos University of Galati, Domnească St 111, \\ Galați, Romania \\ * corresponding author: iuliana.aprodu@ugal.ro
}

Bulletin UASVM Animal Science and Biotechnologies 73(2)/ 2016

Print ISSN 1843-5262; Electronic ISSN 1843-536X

DOI:10.15835/buasvmcn-asb: 12150

\begin{abstract}
Nutritional quality and technological performances of grains can be modulated through germination and controlled fermentation. The aim of the work was to estimate the effect of germination $\left(72 \mathrm{~h}\right.$ at $\left.23^{\circ} \mathrm{C}\right)$ and fermentation on the fundamental rheological properties of the soy flour based suspensions and sourdoughs, and to assess the bread making potential of the whole soy flours by considering the thermo-mechanical functionality of soy in admixture with white wheat flour. Soy flour based sourdough were prepared using three different starter cultures, consisting of mixtures of lactic acid bacteria like Lactobacillus plantarum, Lb. brevis, Lb. rhamnosus, Lb. casei, Lb. acidophilus, Bifidobacterium BB12 ${ }^{\circledR}$, and Streptococcus thermophilus and/or yeast Kluyveromyces marxianus subsp. Marxianus. The rheological behaviour of the suspensions and sourdoughs was influenced by the soy germination and fermentation processes. The stress sweep tests indicated significant narrowing of the linear viscoelastic regions, as well as the decrease of the stress values required for the beginning of flow. The temperature ramp test showed more intense swelling in case of the germinated and fermented samples. Both native and germinated soy flours were used to replace $15 \%$ of the wheat flour, and the Mixolab test indicated that the germination process caused the decrease of protein weakening and dough stability. The sourdoughs addition to the wheat flour resulted in significant changes of the thermo-mechanical properties of the dough. Properties related to stability of starch gel during heating, starch gelatinization and retrogradation depended on the type of starter culture used for fermentation.
\end{abstract}

Keywords: germination, rheological behaviour, soy, sourdough

\section{INTRODUCTION}

Nowadays there is an increased demand of the consumers for foods that provide more than satisfying hunger and nutrients requirements, but also contribute directly to their health (Siro et al., 2008). Therefore, there is a high interest for identifying low-cost food ingredients which offer health benefits, and for developing processing technologies that might allow expanding their functionality, as well as their use in food formulations.

Many studies document the importance of legumes as functional ingredients in some foods, and as therapeutic agents in the diet of healthy vulnerable populations (Campos-Vega et al., 2010; Aguilera et al., 2013; Patrascu et al., 2016). The health promoting ability of vegetables highly depends on the processing, which modulates the level of different bioactive compounds, as well as their activity and bioavailability (Plaza et al., 2003; Rosales-Juárez et al., 2008). Controlled fermentation and germination are among the simplest and less expensive techniques that can be used for improving the nutritive and health qualities of grains. It was reported that during germination the contents of soluble protein and dietary fiber of legumes increase, as well as digestibility. In addition, germination proved to be effective in increasing the overall antioxidant activity, total phenols, catechins, and proanthocyanidins contents in nonconventional legumes like cowpea, jack bean, dolichos and 
mucuna (Aguilera et al., 2013). The increase of the bioactive compounds level of the vegetal products can be also obtained through fermentation, by careful selection of different bacterial strains, or by performing metabolic engineering experiments (Banu et al., 2010; Iyer and Tomar, 2009; Sands et al., 2009).

In some cases the interest in the health aspects of different food products suffers because of the sensory properties, which is a key criterion in consumer choice. In particular, the acceptance of soy is in some cases limited because of the beany taste and the presence of high amounts of lypoxigenase, mainly responsible for the oxidation of unsaturated fatty acids during storage. These disadvantages can be overcome by germination (Shin et al., 2013). Moreover, both germination and fermentation were reported to decrease the level of antinutritive factors commonly present in legumes and pulses (Vidal-Valverde et al., 2002; Aguilera et al., 2013).

The present study is focused on soy flour, which has multiple applications in food industry because of the good functional properties, including water holding capacity, oil binding capacity, emulsifying capacity and dough handling properties (Shin et al., 2013; Patrascu et al., 2016). Concerning the bread making opportunities, the soy flour can be used in admixture with the wheat flour. The recommended substitution level is up $30 \%$, such as to avoid getting bakery products with dense texture and beany flavor (Shin et al., 2013). Rosales-Juárez et al. (2008) reported that, although addition of germinated soy flour to the wheat had no significant influence on the mixing properties of the doughs, resulted in breads with better texture properties and higher specific volume. Shin et al. (2013) showed that soy germination and pre-treatment through heating allow obtaining healthy gluten-free breads, with better loaf volume, texture and flavour with respect to the raw soy flour based ones.

The main objective of the study was to investigate the effect of germination and fermentation on the functionality of soy flour. Different starter cultures consisting on mixtures of lactic acid bacteria and yeast were used for preparing soy flour based sourdoughs. The rheological properties of the native and germinated soy flours and sourdoughs, and the thermo-mechanical properties of wheat flour sourdough mixtures were tested.

\section{MATERIALS AND METHODS \\ Materials}

Commercial white wheat flour (moisture content of $13.18 \%$, protein content of $9.40 \%$, and ash content of $0.48 \%$ ) and dry soybean (Glycine $\max$ L) seeds (Solaris Plant SRL, Bucharest, Romania) retailed on the local market (Galati, Romania) were used in the study. All chemicals used in the experiment were of analytical grade.

Three different starter cultures (SC) were used for the soy flour based sourdough preparation as follows: SC1 - mixture of Lactobacillus plantarum, $L b$. brevis and Lb. rhamnosus (DI-PROX MTTX) from EDR Ingredients, Romania; SC2 - mixture of Lb. casei (Nutrish ${ }^{\circledR}$ ), and yeast Kluyveromyces marxianus subsp. Marxianus (LAF4) from Chr Hansen, Brasov, Romania; SC3 - mixture of Lb. acidophilus, Bifidobacterium $B B 12^{\circledR}$, and Streptococcus thermophilus (ABT-1) from $\mathrm{Chr}$ Hansen, Brasov, Romania.

\section{Germination of soybeans}

The soybeans were rinsed with tap water and sanitised by soaking for 15 min with aqueous ethanol solution (70\%), and finally rinsed with distilled water. The soybeans were then evenly spread on a sterile cotton layer, moistened and germinated at $23^{\circ} \mathrm{C} \pm 1$ for $72 \mathrm{~h}$. The germinated seeds were further dried at $55^{\circ} \mathrm{C} \pm 2$ for $48 \mathrm{~h}$ in a convection oven (LabTech LDO-030E, Daihan LabTech Co., LTD, Kyonggi-Do, Korea).

\section{Flour obtaining}

The dry native and germinated soybeans were milled into flours with particles size lower than $315 \mu \mathrm{m}$ using a laboratory mill (WZ-2, Sadkiewicz Instruments, Bydgoszcz, Poland). The obtained flours were stored in glass containers at $\sim 4^{\circ} \mathrm{C}$ for further tests.

\section{Proximate composition and protease activity}

The proximate composition of the flour samples was determined as follows: the moisture content with the AACC 44-51 method (AACC International, 2000); the protein content through the semimicro-Kjeldahl method (Raypa Trade, R. Espinar, S.L., Barcelona, Spain), using a nitrogen conversion factor of 5.83; ash content using SR ISO 2171: 2002 Method (ASRO 2008). 
The protease activity was determined using casein as substrate by means of the method proposed by Anson (1938).

Preparation of the sourdoughs

The inoculum was prepared according to producer recommendations such as to get a size of $10^{8} \mathrm{cfu} / 100 \mathrm{~g}$ dough. The sourdoughs were prepared in large glass beakers by well mixing the native and germinated whole soy flour with tap water and inoculum, such as to get a final dough yield of 300 . The dough yield was estimated as mass of dough/mass of flour $\times 100$.

The beakers were covered with aluminum foil, and samples were subjected to fermentation at $40^{\circ} \mathrm{C}$ for $20 \mathrm{~h}$ in a laboratory incubator (Pol-Eko Aparatura, Wodzisław Śląski, Poland).

\section{Rheological properties}

The soy flour based suspensions (33\%) and sourdoughs were characterized in terms of rheological properties using a controlled-stress rheometer (AR2000ex, TA Instruments, Ltd, New Castle, DE USA) equipped with a Peltier system for controlling the temperature. All tests were carried out using a plate - plate geometry with the diameter of $40 \mathrm{~mm}$, a closing gap of $2 \mathrm{~mm}$, and a solvent trap to avoid moisture loss. For each tested sample, the linear viscoelastic region (LVR), where storage and loss moduli ( $G^{\prime}$ and $\left.G^{\prime \prime}\right)$ are constant, was first identified through stress sweep tests under small amplitude oscillatory flow, by increasing the stress value from 0 to $100 \mathrm{~Pa}$, at an oscillation frequency of $1 \mathrm{~Hz}$. Moreover, the beginning of flow (also considered to be the yield point) was determined as the stress value where $G^{\prime} / G^{\prime \prime}$ crossover appeared. Dynamic frequency sweeps were performed within LVR at a constant oscillatory stress of $0.1 \mathrm{~Pa}$. In order to observe dough rheological behavior during thermal processing together with its gelling capacities a temperature ramp step was performed, by increasing the temperature with $2{ }^{\circ} \mathrm{C} / \mathrm{min}$ from $20{ }^{\circ} \mathrm{C}$ to $90{ }^{\circ} \mathrm{C}$ maintained 10 minutes. In order to avoid any water evaporation, the tested samples were covered with a solvent trap moistened with 1 $\mathrm{ml}$ water. Because the thermal treatment induces changes of the volume of investigated materials, the test was performed under controlled normal force condition set at $0.2 \mathrm{~N}$ in compression mode. Thus, when the normal force changed because of sample expansion, the gap changed to compensate for the change in the normal force induced by the dimensional change of the sample. The imposed normal force value during temperature ramp test was established as the one presented by doughs in resting conditions at $20^{\circ} \mathrm{C}$ and a closure gap of 2 $\mathrm{mm}$. Gap variation during temperature ramp was used to observe any swelling phenomenon of the doughs. This technique was previously used to assess polymers shrinkage phenomenon during thermal curing (Shah and Schubel, 2010).

Thermo-mechanical properties

The empirical rheological measurements were performed using the Mixolab Chopin (Tripette \& Renaud Chopin, Villeneuve La Garenne, France) and the standard protocol Chopin+.

The soy flour (15\%) and sourdoughs (corresponding to $15 \%$ of soy flour) were added to the white wheat flour directly into the Mixolab tank and further mixing was performed at $30^{\circ} \mathrm{C}$ at a rate of $80 \mathrm{rpm}$. Different water volumes were added to the doughs such as to get a constant C1 torque of about $1.1 \mathrm{Nm}$ at $30^{\circ} \mathrm{C}$. The following typical parameters of the Mixolab curve were registered: $\mathrm{C} 2(\mathrm{Nm})$ gives indication about protein weakening when subjecting the dough to double constraints of mechanical work and temperature; C3, C4 and C5 (Nm) are related to starch behavior and give indications on gelatinization, stability of the gel and retrogradation during the cooling stage, respectively (Collar et al., 2007).

\section{Statistical analysis}

Statistical analysis was done using Microsoft Excel Software. Two independent germination experiments were conducted and the measurements were performed in triplicate. The average values are reported together with standard deviations.

\section{RESULTS AND DISCUSSION \\ Influence of germination and fermentation on the rheological properties of soy flour}

The soybeans were subjected to germination for $72 \mathrm{~h}$ at $23^{\circ} \mathrm{C} \pm 1$ and were then dried to $96.39 \%$ d.w. The germination process caused the increase of the protein content from 36.03 to $41.82 \%$, and had no significant influence on the ash content (5.80 and 5.62 in case of native and germinated soy, respectively).

The results of the stress sweep test are represented in Fig. 1 as G' and G" variation with applied stress. Soy germination determined a significantly narrowing of LVRs for all studied samples $(p<0.05)$ and a significantly reduction on both $G^{\prime}$ and $G^{\prime \prime}$ 
values, reducing also the stress values required for the beginning of flow (G'/G" cross over) (Tab. 1). Sourdoughs obtained from native soy flour presented structure stability until 7-10 Pa of stress, while those obtained from germinated soy flour resisted to stress values up to $\sim 0.8 \mathrm{~Pa}$ without displaying structure changes. The fermentation process was found to significantly influence $(p<0.05)$ the rheological behavior of the soy flour during the stress sweep test. The sourdoughs resulted to be more consistent, having higher G' and G" values, and wider LVRs in comparison to the control sample (unfermented soy flour based suspensions) for both native and germinated soy flour. This phenomenon might be explained by changes in proteins behavior at different $\mathrm{pH}$ values. In this respect Puppo and Afñon (1999) showed that low $\mathrm{pH}$ values (3.5) of soy protein dispersions resulted in increased viscoelasticity which was enhanced by the formation of dimers out of the native $11 \mathrm{~S}$ proteins.

During the frequency sweep test the soy flour based suspensions behaved like soft solids, resembling the perfect cross-linked gel-like structures, with G'values higher than G" values (data not presented). Higher values of the complex modulus $\left(\mathrm{G}^{*}\right)$ were registered for sourdoughs in comparison to the control samples over the entire tested frequency range (Fig. 2). Lower $G^{*}$ values during frequency sweep test in case of non-fermented buckwheat dough in comparison to sourdough was also presented by Moroni et al. (2011). They also observed that sourdough addition to batters resulted in a significantly increase of $\mathrm{G}^{*}$ values.

The rheological behavior of the soy flour based samples while increasing the temperature is presented in Fig. 3a. In case of the suspensions obtained from germinated flour significant lower $G^{\prime}$ values were registered $(\mathrm{p}<0.05)$ at low temperature (Fig. 3a), before the initiation of the gelling process $\left(55-70^{\circ} \mathrm{C}\right)$. However, after gelatinization there were no statistical differences ( $p>0.05)$ between $G^{\prime}$ values of the suspensions obtained from native and germinated soy flour (Tab. 1). In case of the control samples, the $\mathrm{G}^{\prime}$ values after the gelatinization point remained lower compared to the sourdoughs. In this respect Schober et al. (2007) stated that sorghum fermentation caused a significant higher resistance
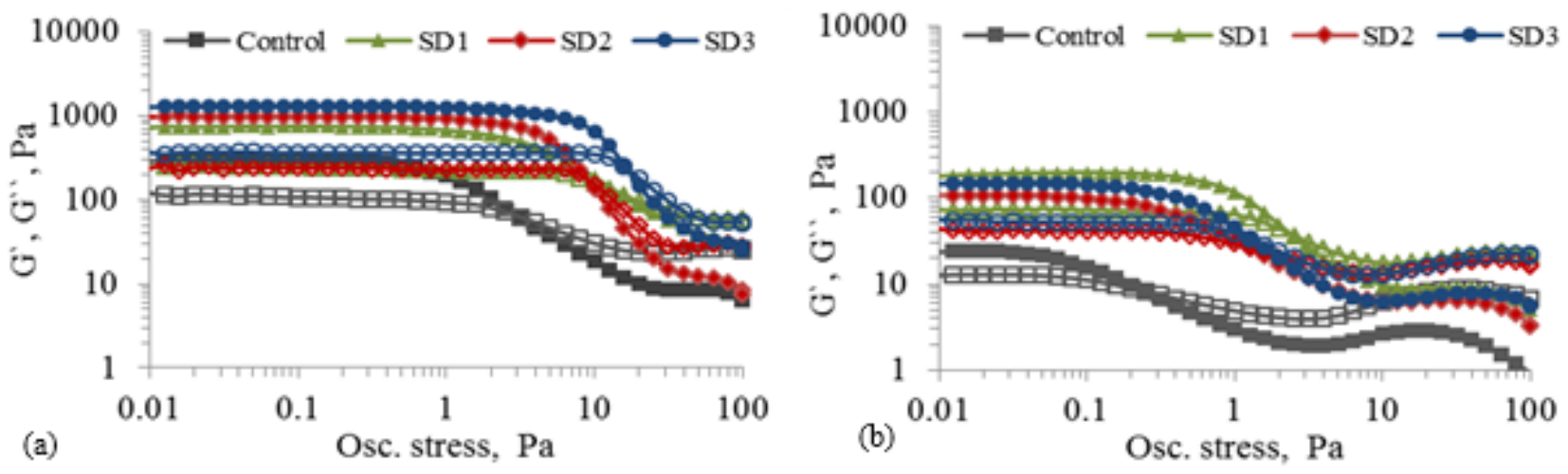

Fig. 1. The evolution of the viscoelastic moduli during stress sweep test for the native (a) and germinated (b) soy flour based samples. Full symbols stand for G'values and open symbols stand for G" values. Control - soy flour based suspension, SD1, SD2, SD3 - sourdoughs fermented with SC1, SC2 and SC3, respectively

Tab. 1. The influence of germination and/or fermentation on some rheological viscoelastic parameters of soy flour based samples

\begin{tabular}{ccccc}
\hline \multirow{2}{*}{ Sample } & \multicolumn{2}{c}{ Stress sweep - Yield stress, Pa } & \multicolumn{2}{c}{ Temperature ramp - Final G`value, Pa } \\
\cline { 2 - 5 } & Non-germinated & Germinated & Non-germinated & Germinated \\
\hline Control & $2.95 \pm 0.2$ & $0.24 \pm 0.0$ & 3485 & 3901 \\
\hline SD1 & $14.66 \pm 1.1$ & $2.38 \pm 0.2$ & 10190 & 18970 \\
\hline SD2 & $8.96 \pm 0.1$ & $1.28 \pm 0.0$ & 12100 & 7614 \\
\hline SD3 & $16.23 \pm 0.7$ & $1.37 \pm 0.0$ & 20040 & 12520 \\
\hline
\end{tabular}


to deformation after gelatinization compared to batters without sourdough.

Another observation during temperature ramp test was that germination and fermentation determined the significant increase of the closing gap in the gelatinization temperature range (Fig. $3 \mathrm{~b}$ ), up to $1 \mathrm{~mm}$ in case of germinated soy flour based sourdoughs, and up to $0.6 \mathrm{~mm}$ in case of native soy flour based sourdoughs. The increased volume of sourdough is due to gas formation during fermentation process (Arendt et al., 2007). The gap increase of control samples was observed to be rather similar for both germinated and native soy. However, the process started much later (at $67-77^{\circ} \mathrm{C}$ ) in comparison to the sourdoughs where gap started to rise at $40-44{ }^{\circ} \mathrm{C}$ in order to compensate the normal force increment.
Influence of germination and fermentation on the thermo-mechanical properties of soy flour containing doughs

The effect of native and germinated soy flour addition on the thermo-mechanical properties of wheat flour dough was assessed by means of Mixolab device (Tab. 2). Water absorption (WA) increased with addition of native soy flour to the wheat flour, and decreased with addition of germinated soy flour compared to the wheat sample. Our results concerning the native soy flour supplemented samples are in agreement with Doxastakis et al. (2002), Indrani et al. (1997) and Rosales-Juárez et al. (2008), who observed WA increases of 1.2 to $6.8 \%$ when adding defatted soy flour and whole soy flour to the wheat flour. The higher protein, fiber and ash contents of the native soy flour compared to the wheat flour might explain the higher amount of water needed

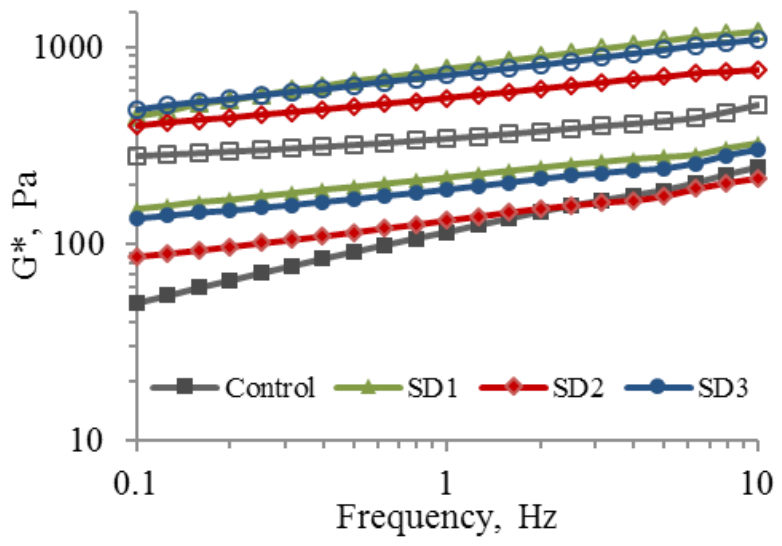

Fig. 2. Viscoelastic behavior of soy flour based samples during frequency sweep test. Full and open symbols stand for germinated and native soy, respectively. Control - soy flour based suspension, SD1, SD2, SD3 - sourdoughs fermented with SC1, SC2 and SC3, respectively
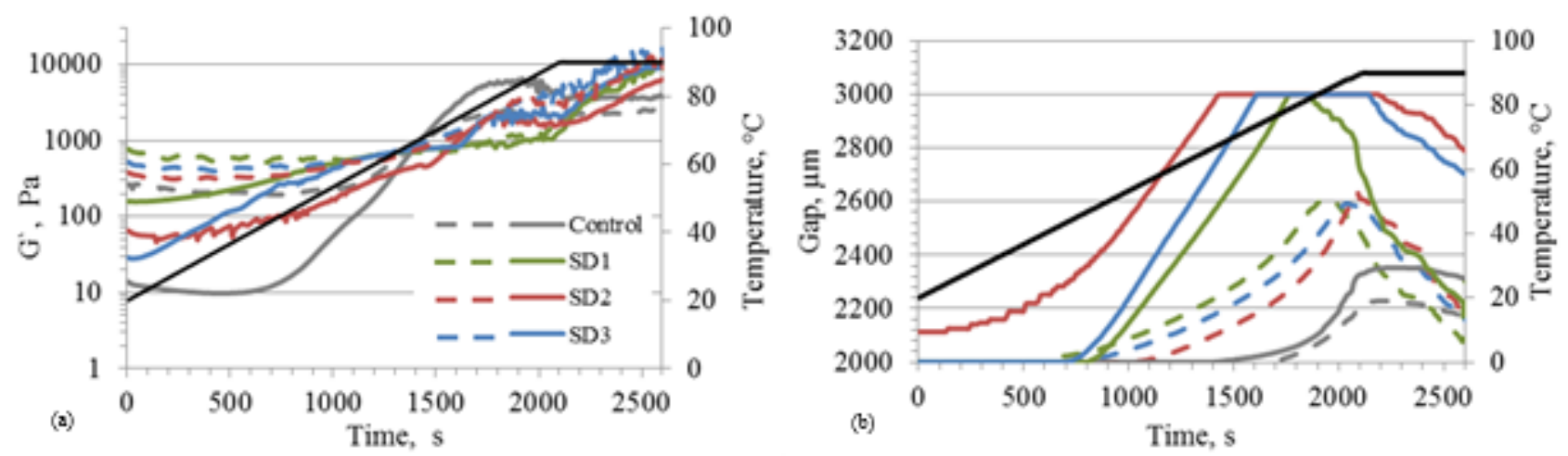

Fig. 3. Viscoelastic behavior of soy flour based samples during temperature ramp test. Full and dashed lines stand for germinated and native soy. Temperature evolution during rheological test is represented in black. Control - soy flour based suspension, SD1, SD2, SD3 - sourdoughs fermented with SC1, SC2 and SC3, respectively 
to get optimum dough consistency (C1 of $1.1 \mathrm{Nm}$ during mixing at $30^{\circ} \mathrm{C}$ ). The torque of $1.1 \mathrm{Nm}$ was obtained faster in case of the wheat flour compared to the samples with native and germinated soy flour (Fig. 4). The slightly lower WA corresponding to the sample with germinated soy might be the effect of increasing the enzymatic activity and/or decreasing the amount of hydrophilic components during germination.

The addition of native and germinated soy flours to the wheat flour decreased dough stability (S), registered during mixing at $30^{\circ} \mathrm{C}$, from 8.28 min to 7.03 and $4.80 \mathrm{~min}$, respectively (Tab. 2). Moreover, the dough consistency (C2) resulting when exposing the dough to double constrain of kneading and temperature (heating by $4^{\circ} \mathrm{C} / \mathrm{min}$ during kneading with $75 \mathrm{rpm}$ ), decreased from $0.45 \mathrm{Nm}$ to 0.43 and $0.33 \mathrm{Nm}$, respectively, as a consequence of protein weakening. The significant lower C2 value for the sample with germinated soy flour can be explained by the activation of proteolytic enzymes during germination. Indeed, the protease activity increased during the $72 \mathrm{~h}$ of germination from $2.50 \mathrm{AU} / 100 \mathrm{~g}$ d.w to 5.75 $\mathrm{AU} / 100 \mathrm{~g}$ d.w.

The addition of native and germinated soy flour to the wheat flour induced the decrease of the C3, C4 and C5 parameters which define the pasting properties of the doughs (Tab. 2). The changes in the pasting properties of the doughs are mainly due to the starch dilution phenomenon that appears when wheat is substituted by soy flour. On the other hand these changes might be also caused by the differences in water distribution within doughs, taking into account that the whole soy flour contains higher amounts of protein, pectins, and hemicellulose, including pentosans (RosalesJuárez et al., 2008) with respect to the white wheat flour. The maximum viscosity during heating (C3) which defines starch gelatinization, decrease from 2.04 to $1.56-1.52 \mathrm{Nm}$ when replacing $15 \%$ of the wheat by soy flour.

Although high differences in terms of the starch gel stability (C4) were registered when comparing the thermo-mechanical behavior of the wheat flour dough $(1.91 \mathrm{Nm})$ and samples with native and germinated soy flour addition (1.22 and $1.15 \mathrm{Nm}$, respectively), no important variation of the cooking stability range (C3-C4) was obtained when diluting the wheat flour. Finally, regardless of the flour type, soy addition to the wheat flour caused a significant decrease of starch retrogradation: the C5 dropped from 2.94 $\mathrm{Nm}$ to 1.91 and $1.71 \mathrm{Nm}$ when supplementing the wheat flour with native and germinated soy flour, respectively.

Tab. 2. Effect of the addition of native (S) and germinated soy (GS) flour to the white wheat flour (WF) on the thermo-mechanical properties of the dough assessed by Mixolab

\begin{tabular}{ccccccc}
\hline Samples & WA, $\%$ & $\mathrm{C} 2, \mathrm{Nm}$ & $\mathrm{C} 3, \mathrm{Nm}$ & $\mathrm{C} 4, \mathrm{Nm}$ & $\mathrm{C} 5, \mathrm{Nm}$ & $\mathrm{S}, \mathrm{min}$ \\
\hline $\mathrm{WF}$ & $57.5 \pm 0.01$ & $0.45 \pm 0.01$ & $2.04 \pm 0.02$ & $1.91 \pm 0.01$ & $2.94 \pm 0.02$ & $8.28 \pm 0.12$ \\
\hline $\mathrm{WF}+\mathrm{S}$ & $59.7 \pm 0.0$ & $0.43 \pm 0.01$ & $1.52 \pm 0.01$ & $1.22 \pm 0.01$ & $1.81 \pm 0.01$ & $7.03 \pm 0.14$ \\
\hline $\mathrm{WF}+\mathrm{GS}$ & $56.8 \pm 0.0$ & $0.33 \pm 0.01$ & $1.56 \pm 0.01$ & $1.15 \pm 0.01$ & $1.71 \pm 0.01$ & $4.80 \pm 0.10$ \\
\hline
\end{tabular}

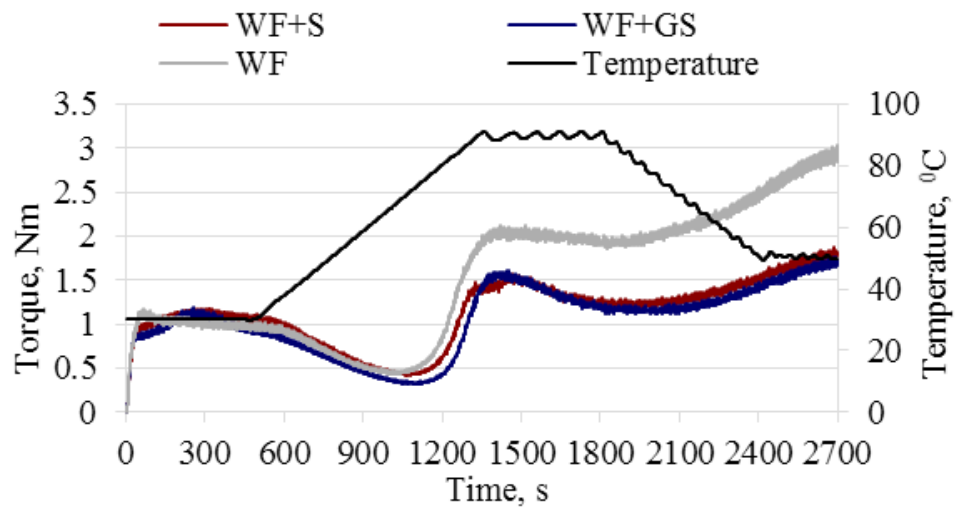

Fig. 4. Mixolab curves of wheat flour (WF) alone or supplemented with $15 \%$ native soy flour $(\mathrm{WF}+\mathrm{S})$ or germinated soy flour $(\mathrm{WF}+\mathrm{GS})$ 
Soy germination caused the decrease of $\mathrm{C} 4$ and C5 values (Tab. 2). The difference in these pasting related Mixolab parameters registered for the samples with different types of soy flour might be explained by the increased amylase activity in the germinated beans. The reduction of torque during heating and cooling is the result of the extensive degradation of starch by amylases activated during germination (Cornejo and Rosell, 2015). The starch gelatinization range (C3-C2) was higher in sample with germinated soy flour (1.23 Nm), compared to the sample with native soy flour (1.09 Nm).

Further tests were meant to investigate the effect of fermentation of the thermo-mechanical properties of the doughs. The type of starter culture used to prepare the sourdoughs influenced dough rheology (Tab. 3 and Fig. 5), most probably due to various metabolites accumulated in sourdough during fermentation. Some of the lactic bacteria present in starter culture mixtures are exopolysaccharides producers (Vasilean et al., 2010).

Regardless of the flour type and the starter culture used for fermentation, the minimum C2 consistency ranged from 0.32 to $0.49 \mathrm{Nm}$ (Tab. 3), in agreement with the optimum values for baked products $(0.37$ to $0.45 \mathrm{Nm}$ ) indicated by Dubat and Boinot (2012). When comparing the dough samples prepared with different starter cultures, the most important differences were registered for C3, C4 and C5 parameters that define starch gelatinization, stability of starch gel during heating and starch retrogradation after cooling of dough from 90 to $50^{\circ} \mathrm{C}$, respectively.
The thermo-mechanical behavior of the dough samples containing sourdoughs prepared with SC1 differed significantly with respect to the samples with SC2 and SC3 (Fig. 5). Among the samples with sourdoughs prepared with SC1, the one supplemented with native soy flour had the highest C3 and the lowest C4 torques. Therefore this sample had the lowest cooking stability, as indicated by (C3-C4) value of $0.36 \mathrm{Nm}$, suggesting that, compared to the other samples, amylase is more active during heating stage.

In case of samples with sourdoughs fermented with SC2 and SC3, the highest values of the C3, C4 and C5 parameters were obtained for the wheat flour doughs and the lowest for the samples supplemented with germinated soy flour. The dough sample containing sourdough from germinated soy flour fermented with SC3 had the lowest $\mathrm{C} 4$ and $\mathrm{C} 5$ values and the highest (C3-C4) value, suggesting higher amylases activity and lower stability of the pasting gel (Banu and Aprodu, 2012), most probably as a consequence of large amounts of dextrins accumulated in dough (Dubat and Boinot, 2012).

\section{CONCLUSION}

Chemical composition of native soy flour, enzymes activity of germinated soy, and the metabolites accumulated in the sourdough during fermentation highly influenced the fundamental rheological properties of the flour based suspensions and sourdoughs, as well as the thermo-mechanical properties of the wheat flout based doughs. A more pronounced swelling phenomenon was observed in case of

Tab. 3. Effect of the addition of native (S) and germinated (GS) soy flour to the wheat flour (WF) on the thermo-mechanical properties of doughs, assessed by Mixolab

\begin{tabular}{cccccccc}
\hline Samples & $\mathrm{C} 2, \mathrm{Nm}$ & $\mathrm{C} 3, \mathrm{Nm}$ & $\mathrm{C} 4, \mathrm{Nm}$ & $\mathrm{C} 5, \mathrm{Nm}$ & $\mathrm{C} 2-\mathrm{C} 3, \mathrm{Nm}$ & $\mathrm{C} 3-\mathrm{C} 4, \mathrm{Nm}$ & $\mathrm{C} 5-\mathrm{C} 4, \mathrm{Nm}$ \\
\hline WF_SD1 & $0.32 \pm 0.01$ & $1.61 \pm 0.01$ & $1.71 \pm 0.01$ & $2.81 \pm 0.02$ & $1.29 \pm 0.01$ & $-0.10 \pm 0.01$ & $1.10 \pm 0.01$ \\
\hline WF+S_SD1 & $0.49 \pm 0.01$ & $1.92 \pm 0.01$ & $1.56 \pm 0.01$ & $2.54 \pm 0.01$ & $1.43 \pm 0.01$ & $0.36 \pm 0.01$ & $0.98 \pm 0.01$ \\
\hline WF+GS_SD1 & $0.33 \pm 0.02$ & $1.51 \pm 0.01$ & $1.61 \pm 0.01$ & $2.14 \pm 0.01$ & $1.16 \pm 0.01$ & $-0.10 \pm 0.01$ & $0.56 \pm 0.01$ \\
\hline WF_SD2 & $0.49 \pm 0.02$ & $2.02 \pm 0.01$ & $2.08 \pm 0.01$ & $3.13 \pm 0.02$ & $1.53 \pm 0.01$ & $-0.06 \pm 0.01$ & $1.05 \pm 0.01$ \\
\hline WF+S_SD2 & $0.36 \pm 0.01$ & $1.83 \pm 0.01$ & $1.90 \pm 0.02$ & $2.96 \pm 0.01$ & $1.47 \pm 0.01$ & $-0.07 \pm 0.01$ & $1.06 \pm 0.01$ \\
\hline WF+GS_SD2 & $0.32 \pm 0.01$ & $1.53 \pm 0.01$ & $1.55 \pm 0.01$ & $2.57 \pm 0.01$ & $1.21 \pm 0.01$ & $-0.02 \pm 0.01$ & $1.02 \pm 0.01$ \\
\hline WF_SD3 & $0.48 \pm 0.01$ & $1.96 \pm 0.01$ & $1.98 \pm 0.02$ & $2.91 \pm 0.01$ & $1.44 \pm 0.01$ & $-0.06 \pm 0.01$ & $0.93 \pm 0.01$ \\
\hline WF+S_SD3 & $0.43 \pm 0.02$ & $1.66 \pm 0.02$ & $1.57 \pm 0.01$ & $2.50 \pm 0.01$ & $1.23 \pm 0.02$ & $0.09 \pm 0.01$ & $0.93 \pm 0.01$ \\
\hline WF+GS_SD3 & $0.41 \pm 0.01$ & $1.51 \pm 0.02$ & $0.97 \pm 0.01$ & $1.45 \pm 0.01$ & $1.12 \pm 0.01$ & $0.56 \pm 0.01$ & $0.48 \pm 0.01$ \\
\hline FD1,SD2 andSD3 sourdough prepared with SC1,SC2 and SC3 starter cultures, respectively & & &
\end{tabular}


the germinated samples during the temperature ramp test. The effect of native and germinated soy flour addition on the thermo-mechanical properties of wheat flour dough, with or without sourdough, was assessed by Mixolab. Our results indicated that soy germination influenced the bread making suitability of the soy flour by decreasing the protein weakening, dough stability, and starch retrogradation, and increasing the starch gelatinization range and cooking stability. The starter cultures used for sourdoughs fermentation mainly influenced the starch related thermo-mechanical properties, such as starch gelatinization, stability of starch gel during heating and starch retrogradation while cooling the dough from 90 to $50^{\circ} \mathrm{C}$.

Acknowledgements. This work was supported by a grant of the Romanian National Authority for Scientific Research and Innovation, CNCS - UEFISCDI, project number PN-II-RU-TE-2014-4-0618.
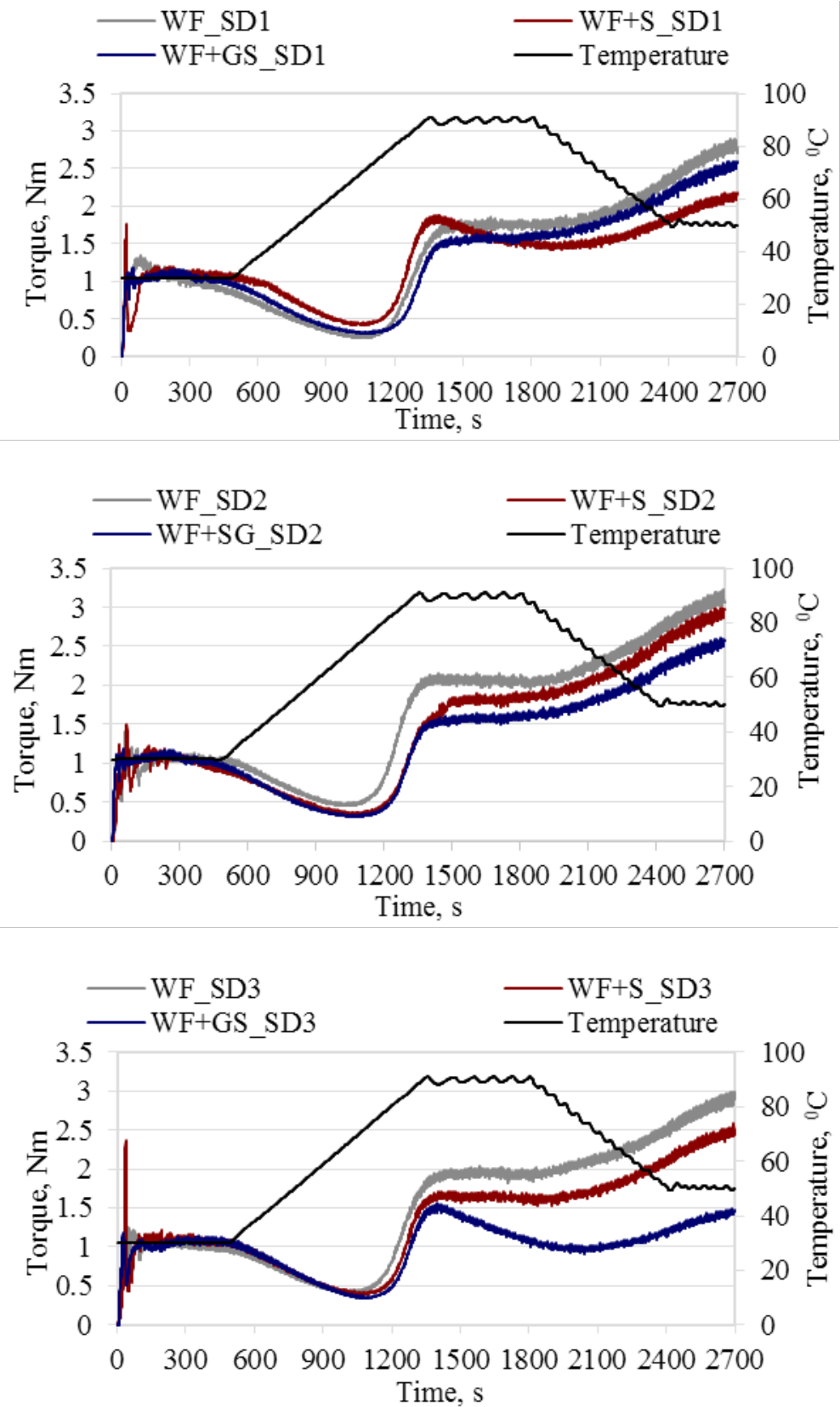

Fig. 5. Mixolab curves of the wheat flour (WF) samples containing 20\% sourdoughs prepared with WF, native soy flour $(\mathrm{WF}+\mathrm{S})$ or germinated soy flour $(\mathrm{WF}+\mathrm{GS})$ and fermented with different starter culture (SD1, SD2, SD3). 


\section{REFERENCES}

1. AACC International. (2000). Approved Methods of the American Association of Cereal Chemists (10th edn. Methods 44-51), Pp. 56-81B. St. Paul, MN: The Association.

2. Aguilera Y, Díaz MF, Jiménez T, Benítez V, Herrera T, Cuadrado C, Martín-Pedrosa M, Martín-Cabrejas MA (2013). Changes in nonnutritional factors and antioxidant activity during germination of nonconventional legumes. J Agr Food Chem 61(34):8120-8125.

3. Anson ML (1938). The estimation of pepsin, trypsin, papain, and cathepsin with hemoglobin. J Gen Physiol 22(1):79-89.

4. ArendtEK, Ryan LA, Dal Bello F (2007). Impactof sourdough on the texture of bread. Food Microbiol 24(2):165-174.

5. ASRO (2008). Romanian standards catalog for cereal and milling products analysis. SR ISO 2171/2002, Bucharest.

6. Banu I, Vasilean I, Aprodu I (2010). Effect of lactic fermentation on antioxidant capacity of rye sourdough and bread. Food Sci Technol Res 16(6):571-576.

7. Banu I, Aprodu I (2012). Studies concerning the use of Lactobacillus helveticus and Kluyveromyces marxianus for rye sourdough fermentation. Eur Food Res Technol 234(5):769-777.

8. Campos-Vega R, Loarca-Piña G, Oomah BD (2010). Minor components of pulses and their potential impact on human health. Food Res Int 43(2):461-482.

9. Collar C, Bollain C, Rosell CM (2007). Rheological behaviour of formulated bread doughs during mixing and heating. Food Sci Technol Int 13(2):99-107.

10. Cornejo F, Rosell CM (2015). Influence of germination time of brown rice in relation to flour and gluten free bread quality. J Food Sci Technol 52(10):6591-6598.

11. Doxastakis G, Zafiriadis I, Irakli M, Marlani H, Tananaki C (2002). Lupin, soya and triticale addition to wheat flour doughs and their effect on rheological properties. Food Chem 77:219-227.

12. Dubat A, Boinot N (2012). Mixolab applications handbook Rheological and enzymes analyses, pp. 10-15, Chopin Technology, Villenueve, France.

13. Indrani D, Savithri GD, Venkateswara-Roa G (1997). Effect of defatted soy flour on the quality of buns. J Food Sci Technol 34(5):440-442.

14. Iyer R, Tomar SK (2009). Folate: a functional food constituent. J Food Sci 74:114-122.

15. Moroni AV, Dal Bello F, Zannini E, Arendt EK (2011). Impact of sourdough on buckwheat flour, batter and bread: biochemical, rheological and textural insights. J Cereal Sci 54(2):195-202.

16. Patrascu L, Vasilean I, Banu I, Aprodu I (2016). Functional properties of pulse flours and their opportunities in spreadable food products. QAS doi: 10.3920/ QAS2015.0770.

17. Plaza L, de Ancos B, Cano PM (2003). Nutritional and health-related compounds in sprouts and seeds of soybean (Glycine max), wheat (Triticum aestivum. L) and alfalfa (Medicago sativa) treated by a new drying method. Eur Food Res Technol 216(2):138-144.

18. Puppo MC, Afñón MC (1999). Soybean protein dispersions at acid $\mathrm{pH}$. Thermal and rheological properties. J Food Sci 64(1):50-56.

19. Rosales-Juárez M, Gonzalez-Mendoza B, Lopez-Guel EC, Lozano-Bautista F, Chanona-Perez J, Gutierrez-Lopez G, Farrera-Rebollo R, Calderon-Domínguez G (2008). Changes on dough rheological characteristics and bread quality as a result of the addition of germinated and non-germinated soybean flour. Food Bioprocess Technol 1:152-160.

20. Sands D, Morris C, Dratz E, Pilgeram A (2009). Elevating optional human nutrition to a central of plant breeding and production of plant-based foods. Plant Sci 177:377389.

21. Schober TJ, Bean SR, Boyle DL (2007). Gluten-free sorghum bread improved by sourdough fermentation: biochemical, rheological, and microstructural background. J Agr Food Chem 55(13):5137-5146.

22. Shin DJ, Kim W, Kim Y (2013). Physicochemical and sensory properties of soy bread made with germinated, steamed, and roasted soy flour. Food Chem 141(1):517523.

23. Shah DU, Schubel PJ (2010). Evaluation of cure shrinkage measurement techniques for thermosetting resins. Polym Test 29(6):629-639.

24. Siro I, Kapolna E, Kapolna B, Lugasi A (2008). Functional food. Product development, marketing and consumer acceptance-A review. Appetite 51(3):456-467.

25. Vasilean I, Neagu C, Aprodu I, Banu I (2010). Production of Microbial Exopolysaccharides in Rye Sourdough. Bulletin UASVM Agriculture 67(2):452-456.

26. Vidal-Valverde C, Frias J, Sierra I, Blazquez I, Lambein F, Kuo YH (2002). New functional legume foods by germination: effect on the nutritive value of beans, lentils and peas. Eur Food Res Technol 215(6):472-477. 